\title{
Speed, Uncertainty, and Origin of Disaster
}

\author{
Thomas Hauer \\ VŠB-Technical University of Ostrava
}

\begin{abstract}
Progress and disaster are two sides of the same coin. Text analyzes the two main themes. Firstly, the treatise attempts at a philosophical analysis of the categories-speed and disaster in Paul Virilio dromology. The development of high technical speeds would thus result in the disappearance of consciousness as the direct perception of phenomena that inform us of our own existence. Dromological research by Paul Virilio presents a critical analysis of the consequences for our perception and logistics caused by polar inertia, inertia of absolute speed. The second part of the study discusses the word-accident. Accident is inseparable from the speed. Virilio's texts deal with the impact of speed, disaster, and accident on the contemporary world. Speed and accident create a new form of uncertainty in society.
\end{abstract}

Keywords: disaster, speed, accident, post-democracy, dromology, uncertainty

The gradual spread of catastrophic events considerably affects the reality of the moment and it causes anxiety and anguish for generations to come. Unexpected and catastrophic events, all accidents, from the most banal to the most tragic, from natural catastrophes to industrial and scientific disasters, make people powerless. As Aristotle said, the accident reveals the substance. If this statement is true, then invention of the substance is equally invention of the accident. The air crash is consequently the futurist invention of the supersonic airliner, just as the Chernobyl meltdown is the invention of the nuclear power station. When we take a look at recent history, the 20th century was the century of great exploits; some of the most significant ones are for example the moon landing, great discoveries in physics and chemistry, or computer science and genetics. However, the 21th century, in turn, reaps the harvest of this hidden production constituted by different disasters. The 20th century did in fact swamp us with mass-producted accidents one after the other.

According to Valèry's postulate,

If consciousness only survives now as awareness of accidents, and if nothing functions except outside consciousness, the loss of consciousness about accidents as well as major disasters would not only amount to unconsciousness but to madness - the madness of deliberate blindness to the fatal consequences of our actions and our inventions. (Virilio 2007, 6)

In contrast to the natural accident, the artificial accident results from the innovation of a motor or of some substantial material. If the substance is absolute and essential to science and if the accident is relative and contingent, we can identify the substance at the beginning of specific fields of knowledge and the accident at the end of the philosophical intuition. "Creation or collapse, the accident is an unconscious oeuvre, an invention in the sense of uncovering what was hidden, just waiting to happen” (Virilio 2007, 9). Accident is inseparable

Thomas Hauer, Prof., Ph.D., Department of Social Science, VŠB-Technical University of Ostrava, Czech Republic; main research field: Postmodern Philosophy, Contemporary Philosophy, Philosophy of Technology, Ethics, and Philosophy of the 20th Century. Email: tomas.hauer@vsb.cz. 
from the speed (Armitage 2000, 38). Virtual speed of unexpected and catastrophic events should be studied instead of the actual speed of objects. As we try to protect ourselves from excess in real speed by means of breaks and automated safety systems, we have to try to protect ourselves from excess in virtual speed, from what unexpectedly happens to substance-meaning to what lies beneath engineer's awareness as producer. In Aristotle's Physics, it is indeed the passage of time, in other words, the speed which destroys and achieves the ruin of all things, and every substance becomes a victim of the accident in the traffic circulation of time.

The production of accidents is connected with the sudden militarization of the sciences, most notably, the fatal invention of weapons of mass destruction and a thermonuclear bomb capable of extinguishing all life on the planet. The visible speed of the substance (that of the means of transport, of computing, of information) is only the tip of the iceberg of the invisible speed of the accident. The speed, with which accidents surge up, plunges humankind into mourning and powerlessness. We have to try as fast as possible to define the flagrant nature of disasters peculiar to new technologies. According to Hannah Arendt: "Progress and disaster are two sides of the same coin” (Virilio 2007, 15). Lately, the accident argument has become one of the mass media's pet themes, the confusion between sabotage and breakdown on the one hand and between the suicide bombing mission and the industrial or other accident on the other hand. Since the start of the 20th century up to the present day, we can see the increase in the number of catastrophes. Artificial accidents have outstripped natural accidents. Suddenly, an accident is no longer unexpected event. It turns into a rumour. One of the cases of catastrophic events is one which emerges in terrorist dimension. There is the confusion between the genuine accident occurring unexpectedly to a substance and the strategy of a malicious act.

Whence the gravity of the New York attack, which calls into question not only the United States's status as a sanctuary, but also the boom in the major airlines and the liberalization of tourist flows, to say nothing of the catastrophic impact of the collapse of the Twin Towers on the comprehensive insurance market. (Virilio 2007, 16)

From such catastrophic events, people face with the ubiquity of risk, often even of a major risk of disaster for humanity. The issue of fear becomes crucial. The speed at which the unknown has been growing expands or intensifies fear (Armitage 2001, 74). Screens have capability to invade the imaginary of populations and perfectly typify the globalization of effects; they act as synchronization of collective emotions greatly favoring the administration of fear. In the near future, this administration of emotions and fear could be run by the movie industry and the mass media replacing the public space of our daily lives. One of the examples is an information accident, in other words, brainwashing designed to sow doubt about the truth of the facts, thereby creating anxiety over diffuse threats whereby any disturbance in perception of events always reinforcing the anguish of the masses. "Suicide bombing or accident? Information or desinformation? From now on, no one really knows” (Virilio 2007, 19).

This example is just one among many. People confronted by this chain of media events, each one more catastrophic than the last, should ask question about the dramatization that has been taking place since the beginning of the 21th century. "With television, which allows hundreds of millions of people to see the same event at the same moment in time, we are finally living through the same kind of dramatic performance as at the theatre in days not long gone" (Virilio 2007, 19-20). The next example is from the field of politics. Nowadays, there is no difference between politics and show business anymore. It is the performance that persuades people that the candidate is sincere. If inventing the substance means indirectly inventing the accident, then, the more powerful and high-performance the invention is, the more dramatic the accident is. 
This statement was evidently confirmed for people throughout the 20th century with the invention of nuclear and thermonuclear weapons that are ultimately unusable. The accident presents in this case the panicstoking uselessness of this type of weaponry. Friedrich Nietzsche wrote in his book, The Birth of Tragedy: "A culture built on science must necessarily perish when it starts to become illogical, that is, to recoil before its own consequences. Our Art reflects this general crisis” (Virilio 2007, 32).

The sudden militarization of science is considered to be necessary to the presumed victory in war. Human power then transforms itself into a cause of ruin, toppling the nations into destruction. This progress in knowledge, from progress in genetics and computer science to the atomic progress, of which Chernobyl is in the wake of Hiroshima, has revealed to us the atrocious truth. This statement perfectly sums up the paradox of the 20th century: "Today, at the very dawn of the 21th century, when much-vaunted globalization is nothing if not the forbidden fruit of the tree of knowledge-in other words, of the so-called information revolution - the exterminator takes over from the predator, just as terrorism takes over from the orifinal capitalism" (Virilio 2007, 33). Extermination becomes the illogical outcome of accumulation. In fact, we can say that this is the accident in knowledge that now rounds off the accident in substances deriving from technoscientific research. If matter has three dimensions, mass, energy, and information, then, after the series of accidents in materials and energy over the past century, the accident is upon us. We should ask ourselves these three questions: Should science reassure? On the contrary, should science frighten? Is science inhuman? Scientific and technical knowledge has many outcomes—radioactive fallout from Chernobyl, genetically modified organisms, reproductive human cloning following on from animal cloning, and this list goes on. "The accident in knowledge is impressive not so much in terms of the number of victims but in the very nature of the risk run" (Virilio 2007, 36). Nowadays, there are many threats to human life such as medically assisted procreation, the right to assisted death and euthanasia, not to mention biological weapons.

Another warning involves the pollution. Alongside the pollution of substances, such as air, water, fauna, flora, there is, at the start of 21th century, the sudden pollution of distances and of the intervals that make up the very density of our daily reality, of this real space of our activities. George Bernanos once wrote: "Luck is like us. Indeed, if once upon a time life was still a theatre, a stage with its transforming sets, daily life has now become sheer luck, a never-ending accident, with many new developments, the spectacle of which is inflicted on us at every moment via our screens" (Virilio 2007, 47). The accident has suddenly become habitable to the detriment of the substance. We can call it integral accident, the accident that integrates us globally and sometimes even disintegrates us physically. In our world, where everything is explained, the accident still remains unexpected, truly surprising, and the unknown quantity. Albert Einstein once said that events do not happen, but they are there and people merely encounter them in passing, in an eternal present. There are not minor incidents on the way; history represents just one long chain reaction. Nagasaki, Hiroshima, Chernobyl are simply instances of momentary inertia and the radioactivity of a place is analogous to the relativity of an instant. The word accident comes from the Latin word accidens, this word signifies what arises unexpectedly in a device, system, or product. It means the unexpected, the surprise of failure or destruction. There are many controversial theories how to avoid accidents that arise from our technological innovations and discoveries. One of them is to directly invent the accident in order to then determine the nature of the famous substance of the product or device discovered. The issue is if people could in this way avert the development of certain supposedly accidental catastrophes. One of the causes of development of tools of destruction is doubtless the scientific and industrial production machine that is the main source of absolute accident that is war-the 
conflict in all societies over the centuries, great war of time.

Great movement of progress of the 19th and 20th century is surely one of the most insidious features covering up the fearful progression, as much industrial as military, in the mode of scientific destruction. The scientists dealing with weapons have become the alchemists of our times. They are working in secret ways, they may never have been in battle, may never have experienced the devastation of war, but they know how to devise the means of destruction. Science has become the arsenal of major accidents. "Currently, what is undermined and everywhere contaminated is science, the whole set of our knowledge literally poisoned by an arms race in weapons of mass destruction that is infesting what we learn and will, if we are not careful, shortly decommission science, making it unavailable to do good" (Virilio 2007, 78). "We are living in a world where we are endlessly confronted with globalization. We can no longer escape a global dimension to being” (Virilio $2010,23)$. What people put on the screen is the technical consciousness, whereas the unconsciousness is the mass of the information circulating within the world of real space at the speed of real time. "The hours will pass, but science will continue to grow" (Virilio 2010, 30). This motto illustrates the notion that science is a lesson in time. Time, which either fades away or which we sum up, thanks to History. As Winston Churchill pointed out at the end of the 1930s, "We are entering the period of consequences" (Virilio 1991, 85). These consequences not only determine the politics of nations but also the science, the human science along with the whole panoply of our knowledge. If science was once a lesson in passing time as well as in the growth of progress, now it is turning into the science of the weather. The uncertain nature of a climate has become the issue of many scientists.

There are many who claim that global warming is catastrophic for the climate. Meteorology has become a very lucrative business for people. However, climatologists do not have a clue what is going to happen because the climate is unpredictable since there is no forecast model that works. There are also other sciences dealing with the issue of climate. One of them is geo-engineering trying to counteract global warming artificially, which involves extremist practices that aim to innovate in the future a universal air conditioning system able to cool down the planet. But for some other climatologists, it is hard to evaluate consequences of such largescale manipulation and they are pessimistic about the effectiveness of such measures. This issue of global warming is just one example of consequence among many other consequences resulting from the progress in science. The 20th century is considered to be the century when people have entered a period of consequences and they have to find effective solutions to save population. The progress in science and technology has resulted in acceleration of time and of everything around us. Nowadays, tendency of adolescents is to opt for chat rooms to maintain contact with others and to form relationships over the internet. The firms such as Google or Yahoo have made this kind of instant messaging service available to people. This proximity without promiscuity has become a market where proximity stops meaning "here” and turns it into the meaning "over there.” Objectivity is transformed into the tele-audiovisual objectivity and face-to-face contact is via an interface, through the view of screens. Warning for people is the loss of sight. The gradual narrowing of the visual field to the frame of the screen can result in eye disease that reduces our lateral vision and that goes by the name of glaucoma. This disease is irreversible and most often painless; it causes a number of optical data to disappear one by one and it can even develop into total blindness. This disease achieves a sort of furtive iconoclasm not of pictorial imagery any more, but of objective ocular imagery and it thereby affects our mental imagery and so our subjectivity—-to the instrumental, teleobjective imagery.

According to Maurice Merleau-Ponty, 
After all, the world is around me, not in front of me, I inhabit it. To suppress, as does the shutter of the screen of a so aptly named terminal, not only lateral vision, but also the countryside, the land around, is to deprive all customary reality of relief and to experience a disastrous reversibility of dimensions, in particular of the depth of perspective. There is no distance any more, we are so close to things, they no longer concern us at all. (Virilio 2010, 79)

Our world has become a foreclosed world by the temporal compression of a realistic acceleration. This sudden reversal in our relationship to the world around us, a result of the acceleration of a real time that dominates, demands training, formation, and sort of tele-scopic education. This is required from the moment the child comes into the world, now accompanied not so much by his parents as by the screen relations that will surround him as an adolescent and as a grown-up in days to come. In 2006, the very first television channel for babies saw the light of day in Europe.

Offering cartoons, nursery rhymes, games, and documentaries, this channel pushing desensitization to and embrace of the acceleration of reality trains the baby in the optically correct perception that will evolve into the aesthetics of his years as a grownup. It thereby promotes toddlers' addiction to the small screen, at the same time as it claims to be protecting those toddlers by drawing the parents' attention to the risks of their progeniture's habituation to the specialized channel's hypnotic effects. (Virilio 2010, 80)

This is happening today even though parents are strongly advised not to leave their very young children in front of the TV. Camille Flammarion may be considered the prophet of this society of accelerating reality which was to lead to the on-line society of instantaneous telecommunications in the 20th century. As the theologian Dietrich Bonhoeffer wrote, "Time is the cycle of light" (Virilio 2010, 87). However, this cyclical time of seasons and days is now doubled by the real time of an instantaneity that is the cycle of the speed of light waves which convey the information of image and sound. The phrase from Joseph Losey's film The Damned, accurately illustrates contemporary world: "It is too late to have a private life" (Virilio 2010, 89). We live in the age of general interactivity where electronic cooperation and collective intelligence could turn humanity as a social corpus not into single people, but into a single mass media corpus.

\section{Works Cited}

Armitage, John. Paul Virilio: From Modernism to Hypermodernism and Beyond. London: Sage Publications, 2000.

---. Virilio Live (Selected Interviews). London: Sage Publications, 2001.

Virilio, Paul. Speed and Politics. Trans. M. Polizzotti. New York: Semiotext(e), 1986.

---. The Aesthetitics of Disappearance. Trans. P. Beitchman. New York: Semiotext(e), 1991.

---. The Vision Machine. Trans. J. Rose. London: British Film Institute, 1994.

---. The Original Accident. Cambridge: Polity Press, 2007.

---. The University of Disaster. Cambridge: Polity Press, 2010. 